\title{
DEVELOPING WASPAS-RTB METHOD FOR RANGE TARGET-BASED CRITERIA: TOWARD SELECTION FOR ROBUST DESIGN
}

\author{
Ali JAHAN \\ Department of Industrial Engineering, Semnan Branch, Islamic Azad University, Semnan, Iran
}

Received 25 April 2016; accepted 11 February 2017

\begin{abstract}
Recently, considerable attention has been devoted to application of multi-attribute decision-making (MADM) method in materials selection. Normalization can be considered as a foundation for rational MADM methods, which should deal with target-based criteria in addition to cost and benefit criteria. Although a good number of applications have been reported for point target criteria in MADM problems, in selection problems related to engineering design, it might be better to let the material and design criteria vary over a range in order to increase flexibility in subsequent design stages. The mentioned point supports a readily adaptable design in changing the customer requirements, which is also significant in offering a robust design. In this research, performance of three promising target-based normalization methods was investigated using simulation experiments to examine the effect of simulation parameters. The effect of parameters and normalization methods was examined using analysis of variance (ANOVA). Moreover, the best structure formula was identified to propose an inclusive range target-based normalization method. The suggested normalization method was used to enhance the capability of Weighted Aggregated Sum Product Assessment (WASPAS) method and applied to a real-word problem dealing with benefit-, cost-, and point target-based criteria as well as the range criterion.
\end{abstract}

Keywords: target-based criteria in MADM, ANOVA, selection, normalization, robust design, WASPAS-RTB.

JEL Classification: C02, C44, D81.

\section{Introduction}

Changing the material set in an already established technology is a rare event and can be considered as a revolution. Traditionally, selection of a new material was usually carried out by resorting to previous experiences or applying "trial-and-error" scheme. Recently, there has been an increasing interest in the subject of multi-attribute decision-making (MADM) methods applied to material selection and design (Alemi-Ardakani et al. 2016; Hafezalkotob

*Corresponding author. E-mails: iranalijahan@yahoo.com,a.jahan@semnaniau

This is an Open Access article distributed under the terms of the Creative Commons Attribution License (http://creativecommons. org/licenses/by/4.0/), which permits unrestricted use, distribution, and reproduction in any medium, provided the original author and source are credited. 
et al. 2016a; Xue et al. 2016; Chatterjee et al. 2011) to avoid utilization of inappropriate materials and make sure that costs are kept to a minimum. Searching for suitable materials is a key part of engineering design process and is a prerequisite for solving a chain of different engineering selection problems such as process, machine, tool, supplier, and even personnel selections. In most of MADM methods, dimensionless or normalization of decision matrix elements is one of the crucial steps; however, it is found that most of the current normalization methods have shortcomings in tackling all necessary requirements (Jahan, Edwards 2015). While many normalization methods may appear to be minor variants of one another, these nuances can have important consequences for inference and decision-making processes. Furthermore, design decision-making matrix consists of target criteria in addition to cost and benefit criteria. However, normalization methods considering target criteria have received much less attention. Target criteria are applicable in many areas, especially implant material selection in which the material must possess properties identical to those of human tissues (Bahraminasab, Jahan 2011). In another example explained by Stanujkic et al. (2013) addressing computer selection, IT specialists can provide some recommendations (preferences/targets) in relation to characteristics of computers. An alternative, i.e. computer, whose performances are equal to desirable performances, compared to all attributes, is potentially the best alternative. Furthermore, target criteria are crucial in patch repair material selection applications ranging from aerospace to rehabilitation of reinforced concrete structures in maintenance of infrastructures, where the repair materials should have similar properties to those of the main material considering a number of criteria such as thermal expansion coefficient. Furthermore, sometimes in some applications for evaluating alternatives in presence of defined criteria/optimal values in standards and/or regulations, target criteria should be met (Zavadskas et al. 2016; Adan et al. 2007). Difficulties arise when a point target criterion is extended to range. Early in the design timeline, some of the design requirements may be uncertain. Rather than setting point targets, in order to increase flexibility in the following design stages, the material and design criteria can be allowed to vary over a range. There are even less methods introduced for normalization of criteria and ranking of material and design selection problems with range target-based criteria. This study first presents a brief overview of the recent history of MADM addressing material selection, normalization methods, and applications of WASPAS approach, describes the observed gap in previous studies, and finally specifies the objectives of the current study. Section 2 is divided into three subsections. The first subsection describes a preliminary method for addressing the following question "What are the limitations of current point target-based normalization methods and which approach is the best one?" The second subsection proposes a range target-based normalization method, and the last subsection describes how the method can enhance the capability of Weighted Aggregated Sum Product Assessment (WASPAS) method. The first part of section 3 presents the results of simulation analysis described in section 2.1, and then applicability of the suggested tool is exemplified through a material selection case study in section 3.2. In section 4, effectiveness of the new method as well as the role of range target-based criteria in material selection to offer a robust design is further discussed. The final section concludes with inferences provided by the undertaken research. 


\section{Literature review}

The pertinent literature has been reviewed attending to material selection methodologies, normalization methods in MADM, and applications of WASPAS method. The recognized research gap as well as objectives of the current study is presented after thorough review of the literature.

\subsection{Brief literature review on application of MADM method in material selection}

Seminal works on material selection in the light of multi-criteria decision-making (MCDM) method were undertaken by Ashby research group (Ashby 1989, 2000; Sirisalee et al. 2004, 2006). An array of studies conducted by Edwards discussed strategic substitution of new materials for old ones (Edwards 2004), selecting materials for optimum use in engineering components (Edwards 2005), and also supporting design decision-making (Edwards, Deng $2007)$ in the subject. Farag $(2013,2008)$ described the quantitative methods employed for material selection and substitution. As Ashby et al. (2004) states: "Achieving the match with design requirements involves four basic steps. (1) A method for translating design requirements into a specification for material and process. (2) A procedure for screening out those that cannot meet the specification, leaving a subset of the original menu. (3) A scheme for ranking the surviving materials and process, identifying those that have the greatest potential. (4) A way of searching for supporting information about the top-ranked candidates" (p.1). Surveys such as those conducted by Sapuan et al. (2009) and Brifcani et al. (2012) have described that a vast array of materials with diverse properties available to the designers make the material selection process a difficult and time-consuming task. Jahan et al. (2010) have shown that a growth in studies addressing material evaluation and selection problems using the MCDM approaches has been observed from 2006. Over recent years, there has been an increasing amount of literature both on development of new MADM methods for material selection (Kabir, Lizu 2016; Hafezalkotob et al. 2016b; Shan et al. 2016; Ardeshirilajimi et al. 2015) and real applications (Al-Oqla, Sapuan 2016; Al-Oqla et al. 2016; Mastura et al. 2016; Hafezalkotob, A., Hafezalkotob, A. 2016; Ishak et al. 2016; Alemi-Ardakani et al. 2015). However, if decision-making models could be developed based on the nature of engineering design problems, more official applications can be reported.

\subsection{Brief literature review on normalization methods of selection criteria}

MADM models are defined by a decision matrix which has the following parts: alternatives $A_{i}(i=1, \ldots, m)$ which decision makers have to choose, criteria $C_{j}(j=1, \ldots, n)$, and element $r_{i j}$ which is the rating of alternative $i$ with respect to criterion $\mathrm{j}$ as shown in Table 1. Furthermore, $r_{j}^{\max }, r_{j}^{\min }, \sigma_{j}, T_{j}$ are the maximum value in alternatives associated with criterion $j$, minimum value in alternatives associated with criterion $j$, standard deviation of $r_{i j}(i=1, \ldots$, $m$ ), and target value for criterion $j$, respectively. Performance ratings for different criteria are measured by different units; however, all the elements must be dimensionless in the decision matrix to offer a valid comparison. The mentioned point is very significant in material selection in which the same material properties may be measured in different convertible units. 
Table 1. A typical multiple attribute decision-making problem

\begin{tabular}{c|cccc} 
& $C_{1}$ & $C_{2}$ & $\ldots$ & $C_{n}$ \\
\hline$A_{1}$ & $r_{11}$ & $r_{12}$ & $\ldots$ & $r_{1 n}$ \\
$A_{2}$ & $r_{21}$ & $r_{22}$ & $\ldots$ & $r_{2 n}$ \\
$A_{3}$ & $r_{31}$ & $r_{32}$ & $\ldots$ & $r_{3 n}$ \\
$\vdots$ & $\vdots$ & $\vdots$ & & $\vdots$ \\
$A_{m}$ & $r_{m 1}$ & $r_{m 2}$ & $\cdots$ & $r_{m n}$
\end{tabular}

The normalization process must eliminate units of criterion functions without exerting any effects on the final result (Opricovic, Tzeng 2004).

A number of matters including capability of removing the scales, symmetry in normalization for cost and benefit criteria, transforming other types of criteria to the benefit ones, rank reversals, and handling negative values are important aspects worth considering for evaluation of the efficiency of normalization methods (Jahan, Edwards 2015). Figure 1 presents the mentioned important aspects that must be considered in developing a normalization method. Capability of removing the scales is a basic rule, which means that in the case of normalizing identical data with different units or scales, the same results should be obtained. Symmetry of normalized values, when comparing cost and benefit criteria, is another chief aspect in evaluating normalization methods. Some methods just remove the scale of criteria; but they cannot convert cost criteria to benefit criteria. Although such a transformation is not necessary for all MADM methods, it usually reduces the calculations required to be performed in the subsequent stages. Phenomenon of rank reversals is another issue, in which the ranking changes when an alternative is added to or removed from the decision problem. In some cases, this may lead to what is called total rank reversal, where the order of preferences is totally inverted. The reason for rank reversal can be application of an improper normalization technique (Barzilai, Golany 1994). The last expected property for normalization methods is capability of presenting acceptable normalized values when there are negative values in the decision matrix.

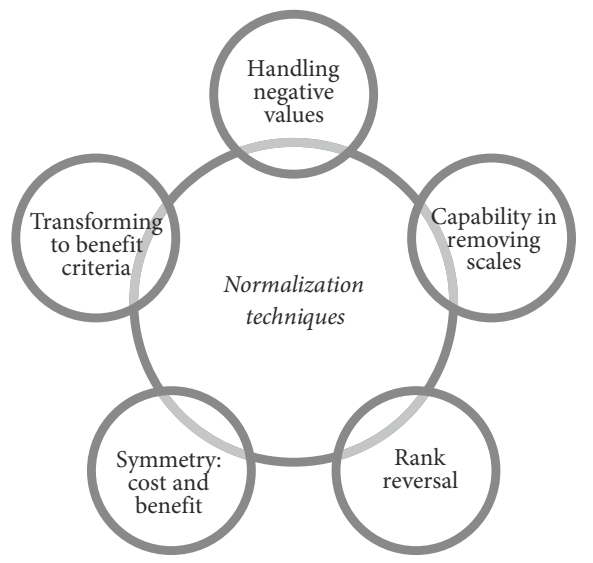

Figure 1. Expected properties for normalization methods 
Milani et al. (2005) compared the effect of some well-known normalization methods on ranking of alternatives in a material selection case study. Similarly, in a critical review of normalization methods, Peldschus (2008) compared various normalization approaches. In a pioneering research, Zavadskas and Turskis (2008) proposed a new logarithmic dimensionless approach that may be more appropriate for situations in which the values of criteria differ considerably. The proposed method is recently used for multi-criteria analysis of projects' performance in construction (Zavadskas et al. 2014a). Celen (2014) used four popular normalization procedures in context of TOPSIS method to evaluate the financial performances of Turkish deposit banks. Nayak et al. (2014) analyzed the impact of various normalization methods on four intelligent forecasting models i.e. a simple ANN model trained with gradient descent (ANN-GD), genetic algorithm (ANN-GA), a functional link artificial neural network model trained with GD (FLANN-GD), and genetic algorithm (FLANN-GA). Stanujkic et al. (2013) pointed to cases where decision-makers expressed their preferences for each selection criteria. Therefore, they extended the linear scale transformation Max-Min method to include the preferred performance ratings (point target). Stanujkic and Zavadskas (2015) presented a modified simple additive weighting (SAW) method based on decision-makers' preferred levels of performances. Jahan and Edwards (2015) identified, classified, and evaluated thirty-one normalization methods for application in material selection problems. The examined methods also included those normalize target-based criteria in addition to cost and benefit criteria. Vafaei et al. (2016) investigated the most appropriate normalization techniques for the Analytical Hierarchy Process (AHP) multi-criteria method by taking into account five normalization methods.

\subsection{Literature review on applications of WASPAS method}

Weighted Aggregated Sum Product Assessment (WASPAS) is one of the most recently developed MADM methods which was originally proposed by Zavadskas et al. (2012). It is the mixture of two well-known MADM approaches, the weighted sum model (WSM) and the weighted product model (WPM). Applications and developments of WASPAS method have been reported in many studies. It was used for assessment and selection of appropriate solutions for occupational safety (Dejus, Antucheviciene 2013). Capability of WASPAS for exact ranking of alternatives was shown by solving eight manufacturing selection problems (Chakraborty, Zavadskas 2014). An extended version of WASPAS method for application in uncertain decision-making environments was proposed by Zavadskas et al. (2014b). In the proposed method, decision-maker(s)' uncertainty in stating their judgments and evaluations with respect to criteria importance and/or alternatives performance on criteria was expressed by interval-valued intuitionistic fuzzy numbers (IVIF). Furthermore, WASPAS was utilized to evaluate and rank alternative applications of nanotechnology, as one of the main and strategic industries in Iran, for future planning (Ghorshi Nezhad et al. 2015). Moreover, WASPAS with fuzzy values was applied to select the best shopping center construction site in Vilnius (Turskis et al. 2015). In another study, WASPAS with Grey Values was implemented for selecting the right contractor in construction industry due to its capabilities in handling imprecise information. To assess existing dwelling houses and refurbish them to satisfy en- 
ergy efficient requirements and humans' needs, the MADM-opt method was developed and applied in the WASPAS technique (Zavadskas et al. 2016). Together, these studies indicate that WASPAS method enjoys wide acceptance.

\subsection{Gap of previous studies and objectives of the current research}

Review of the literature indicates that in areas such as material selection, where numerous choices with similar performances exist and a lot of various criteria influence the selection results, a more precise normalization and of course MADM approach would be required. Reviewed studies in section 1.2 have only dealt with normalization of decision matrix with consideration of just cost and benefit criteria; while few of them have included point targetbased criteria, which are important in many MADM problems including material selection. No attention has been devoted to the effectiveness of point target-based normalization methods, particularly with application of ANOVA analysis. Early in the design timeline, some of the design requirements may be uncertain. There are even less methods introduced for normalization of material and design selection problems with range target-based criteria. In order to increase flexibility in the later design stages, target value of material and design selection criteria can be allowed to vary over a range to increase flexibility in subsequent design stages. Therefore, this study aims at extending the scope normalization research to range target-based criteria (Perez et al. 2016).

The major contributions of this paper are: (1) comparing efficiency of point target-based normalization methods using a systematic approach, (2) developing a new normalization method for addressing range target-based criteria in addition to cost and benefit criteria, (3) addressing the gap in the WASPAS literature for problems involving target criteria, and (4) providing an example on material selection to elucidate details of the proposed method as well as the concepts of point and range target-based criteria.

\section{Materials and methods}

\subsection{Simulation analysis of Point Target-based normalization methods}

Computer simulation was used to compare the promising target-based normalization methods listed in Table 2. The reason for using simulation was its flexible and versatile method, which allows generating a range of problems, and replicating them several times. This provides a vast database of results from which we can study the patterns of solutions provided by different factors.

For this research the simulation study is conducted as follows:

Step 1: Creating table of full factorial simulation experiments with respect to the following factors, in which each random number is generated from independent normal distribution (here $\mu=45$ ). The range constitutes a vector or a $\mathrm{m} \times 1$ matrix.

- Factor A, Location of target value: Lower than all data, Between data, Higher than all data.

- Factor B, Variability or standard deviation of data: Low $(\sigma=3)$, High $(\sigma=30)$.

- Factor C, Number of alternatives: Low $(m=4)$, High $(m=15)$.

- Factor D, Normalization methods: Norm (1), Norm (2), Norm (3). 
Table 2. Promising normalization methods for cost, benefit, and target criteria

\begin{tabular}{|c|l|c|}
\hline Number & Normalization method & Formula \\
\hline $\begin{array}{c}\text { Norm } \\
(1)\end{array}$ & Non-monotonic normalization (Shih et al. 2007) approach & $n_{i j}=e^{\frac{\left(r_{i j}-T_{j}\right)^{2}}{-2 \sigma_{j}^{2}}}$ \\
\hline $\begin{array}{c}\text { Norm } \\
(2)\end{array}$ & Comprehensive normalization method (Jahan et al. 2011) & $\frac{\left|r_{i j}-T_{j}\right|}{\min \left\{r_{j}^{\min }, T_{j}\right\}-\max \left\{r_{j}^{\max }, T_{j}\right\}}$ \\
\hline $\begin{array}{c}\text { Norm } \\
(3)\end{array}$ & Target-based normalization technique (Jahan et al. 2012) & $1-\frac{\left|r_{i j}-T_{j}\right|}{\operatorname{Max}\left\{r_{j}^{\max }, T_{j}\right\}-\operatorname{Min}\left\{r_{j}^{\min }, T_{j}\right\}}$ \\
\hline
\end{tabular}

The range for the factors is typical of those found in many material selection applications. Two levels for variability and three levels for target values were assumed. This is representative of a typical MADM problem. To keep this simulation size manageable, number of replications is 10 for each combination, thus producing ( 3 target value levels $) \times(2$ variability levels $) \times(2$ Number of alternatives levels $) \times(3$ Normalization methods levels $) \times(10$ replications) $=360$ vectors of data.

Step 2: Generates experimental designs table (Using Design Expert software version 7) according to the factors defined in stepl. The simulated vector of data is defined as $r_{i j}, i=1,2$, $\ldots, m$ for a hypothetical criterion $j$.

Step 3: Measure angel between vector of original data (generated in step 2) and vector of normalized values. In multi criteria analysis problems, among various ways to represent the conflict between alternatives, Deng (2007) used the concept of alternative gradient to represent the conflict of decision alternatives. Here this idea is applied to measure the degree of conflict between the original data (rate of alternatives for the hypothetical criterion $j$ ), and normalized values. However, the differences can be also measured by the correlation coefficient.

Assuming that $O$ and $N$ are the original data and normalized values for a specific criterion, respectively, these two groups of data can be considered as two vectors in the " $\mathrm{m}$ " dimensional space. The angle between $O$ and $N$ in the " $m$ " dimensional space can be a good measure of conflict between original data and normalized values. As shown in Figure 2, $O_{i}$ and $N_{j}$ is in no conflict if $\theta_{i j}=0$, the conflict is possible if $\theta_{i j} \neq 0$ i.e. $\theta_{i j} \in\left(0, \frac{\pi}{2}\right)$. This occurs

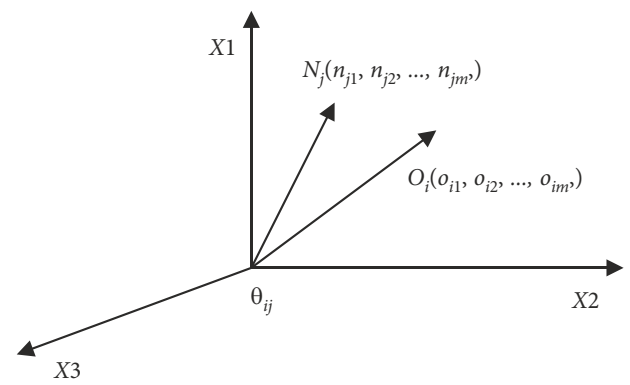

Figure 2. Degree of conflict between original data and normalized one 
because when $\theta_{i j}=0$ the gradients of both the alternatives $O_{i}$ and $N_{j}$ are simultaneously in the same increasing direction and there is no conflict between them. The degree of conflict between alternatives $O_{i}$ and $N_{j}$ is determined by Eq. (1). $\left(r_{i 1}, r_{i 2}, \ldots, r_{i m}\right)$ and $\left(n_{j 1}, n_{j 2}, \ldots, n_{j m}\right)$ are the elements of $O_{i}$ and $N_{j}$ respectively, where $\theta_{i j}$ is the angle between the gradients of the two vectors.

$$
\cos \theta_{i j}=\frac{\sum_{k=1}^{m} n_{i k} r_{j k}}{\left[\left(\sum_{k=1}^{m} n_{i k}^{2}\right)\left(\sum_{k=1}^{m} r_{j k}^{2}\right)\right]^{1 / 2}} .
$$

Step 4: Evaluate the effect of each factor and possible interactions using Design Expert software version 7 .

\subsection{Extension of Point Target-based normalization to range}

Target criteria are applicable in many MADM problems, including medical decision making, design selection, and materials selection in particular biomedical material selection where the biomaterial properties should be as close as possible to the replacing tissue. Target criteria, either point or range, can be also used in patch repair material selection for different applications, ranging from aerospace to rehabilitation of reinforced concrete structures in the maintenance of infrastructures. In criteria, such as modulus of elasticity and thermal expansion coefficient, the repair materials must be compatible with the main body material. Furthermore, sometimes in some applications, to evaluate alternatives in the presence of criteria defined in standards and/or regulations, target criteria should be met.

Recently, two methods were suggested for range target-based normalization. Zeng et al. (2013) proposed VIKOR method with enhanced accuracy to overcome the shortcoming of traditional VIKOR that works only in handling benefit and cost attributes. Eqs. (2-3) show the proposed normalization formula for handling criteria with range targets as well as cost and benefit criteria, respectively. Zeng et al. (2013) ranked iodine deficiency disorder in ten regions using three benefit criteria and two range target-based criteria.

$$
n_{i j}= \begin{cases}\frac{r_{i j}-\mathrm{C}}{\sum_{i=1}^{m}\left(r_{i j}-\mathrm{C}\right)} & \text { if } r_{i j}>\mathrm{C} ; \\ \frac{\mathrm{B}-r_{i j}}{\sum_{i=1}^{m}\left(\mathrm{~B}-r_{i j}\right)} & \text { if } r_{i j}<\mathrm{B} ; \\ 1 & \text { if } \mathrm{C} \leq r_{i j} \leq \mathrm{B} .\end{cases}
$$

In medical decision-making, most patient data (e.g. a laboratory test report) have normal reference ranges. For an attribute with normal distribution, the normal reference range is usually defined as the set of values that $95 \%$ of the normal population falls within. Therefore, in Eq. (2), B can be obtained from $\mu-1.96 \times \sigma$, and $C$ is $\mu+1.96 \times \sigma$. If the rate of alterna- 
tive "i" for criterion " $j$ " falls inside the historical normally distributed data (B and C), the normalized value will be 1 . In addition, Eq. (3) was proposed for cost and benefit criteria.

$$
n_{i j}=\left\{\begin{array}{l}
\frac{r_{j}^{\max }-r_{i j}}{\sum_{i=1}^{m}\left(r_{j}^{\max }-r_{i j}\right)} \text { for benefite criteria; } \\
\frac{r_{i j}-r_{j}^{\min }}{\sum_{i=1}^{m}\left(r_{i j}-r_{j}^{\min }\right)} \text { for cost criteria. }
\end{array}\right.
$$

As presented in Figure 1, the normalization approach must fulfill several properties. However, the main weakness of this method is the failure to remove the scales precisely. While it is a basic rule that in normalizing identical data with different units or scales, the same results must be obtained. For example, density has units $\left[\mathrm{kg} / \mathrm{m}^{3}\right]$ or $\left[\mathrm{g} / \mathrm{cm}^{3}\right]$; for temperature, the Fahrenheit (TF) scale is used in the U.S.A., but most of the rest of the world use the Celsius (TC) scale, and in science, it is often more convenient to use the Kelvin (TK) scale $\left(T_{F}=9 / 5 T_{C}+32, T_{C}=T_{K}-273\right)$. These "convertible" units affect material properties such as heat transfer coefficient or thermal conductivity. Normalization methods must be able to eliminate the 'convertible' units of criterion functions, $\left(\varphi_{i j}=\alpha^{*} r_{i j}+\beta\right)$, and return the same result for all scales. It was shown in (Jahan, Edwards 2015), the sum-based normalization methods including Eqs. (2 and 3) suffer from this shortcoming.

Perez et al. (2016) presented a range target-based normalization method (Eq. (4)) in the context of Reference Ideal Method (RIM). They described the method using an example concerning personal selection (driver). Perez et al. (2016), indicated that, in practice, the ideal solution is not necessarily one of the extreme values, but may be, in fact, a value somewhere in between. In the case of driver selection, if the age is one of the criteria, the desired age for candidate person should be between 30 and 35 years old. Assume that the age range of our candidates is between 23 to 60 years old; it is then evident that those methods that cover only cost and benefit criteria or even point target-based criteria do not work in such situations. Figure 3 demonstrates the schematic of the relation between data and normalized values based on Eq. (4).

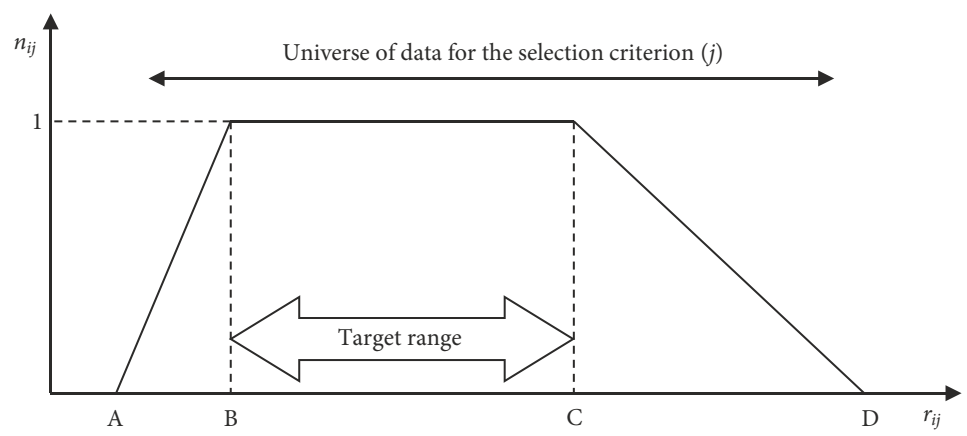

Figure 3. Normalized values and variation of target range in the universe of discourse 
According to the location of $r_{i j}$, three formulas are presented for normalization in Eq. (4). Where the interval $[B, C]$ is the reference ideal and the interval $[A, D]$ is a range that belongs to a universe of discourse $\left(r_{i j} \in[A, D]\right)$. The more distance of $r_{i j}$ from the reference ideal is, the less the normalized value is.

$$
n_{i j}= \begin{cases}1-\frac{\min \left\{\left|r_{i j}-\mathrm{B}\right|,\left|r_{i j}-\mathrm{C}\right|\right\}}{|\mathrm{D}-\mathrm{C}|} & \text { if }\left(\mathrm{C}<r_{i j}<\mathrm{D}\right) \wedge(\mathrm{C} \neq \mathrm{D}) ; \\ 1-\frac{\min \left\{\left|r_{i j}-\mathrm{B}\right|,\left|r_{i j}-\mathrm{C}\right|\right\}}{|\mathrm{B}-\mathrm{A}|} & \text { if }\left(\mathrm{A}<r_{i j}<\mathrm{B}\right) \wedge(\mathrm{A} \neq \mathrm{B}) ; \\ 1 \quad & \text { if } \mathrm{C} \leq r_{i j} \leq \mathrm{B} .\end{cases}
$$

Let us consider the age criterion, such that the range is $[A, D]=[23,60]$, the target range is the $[B, C]=[30,35]$. Considering the two values of, $x=25$ and $x=40$, with the same distance from the targets $(\mathrm{B}-5=25$ and $\mathrm{C}+5=40)$, the normalized values will be obtained, based on Eq. (4), as follows:

$$
\begin{aligned}
& r_{i j}=25 \Rightarrow n_{i j}=1-\frac{\min \left\{\left|r_{i j}-\mathrm{B}\right|,\left|r_{i j}-\mathrm{C}\right|\right\}}{|\mathrm{B}-\mathrm{A}|}=1-\frac{\min \{|25-30|,|25-35|\}}{|30-23|}=0.286 ; \\
& r_{i j}=40 \Rightarrow n_{i j}=1-\frac{\min \left\{\left|r_{i j}-\mathrm{B}\right|,\left|r_{i j}-\mathrm{C}\right|\right\}}{|\mathrm{D}-\mathrm{C}|}=1-\frac{\min \{|40-30|,|40-35|\}}{|60-35|}=0.8 .
\end{aligned}
$$

It is expected to observe the same normalized values, when there is the same distance from the target ranges. Although the presented normalization method (Perez et al. 2016) fulfils most of the requirement of an ideal normalization approach, it seems that it had accentuated the problem of asymmetry in the normalized values so that it can influence the result of MADM. In order to preserve the maximum initial information in relation to initial attribute values and values of other criteria, it is necessary to check the symmetry of normalized values in comparing cost, benefit, and target-based criteria.

The evidence presented in this section suggests the need for a more comprehensive normalization method. Eq. (5) describes the proposed formula for range target-based criteria for possible application in MADM techniques.

$$
n_{i j}= \begin{cases}1-\frac{\min \left\{\left|r_{i j}-T_{u j}\right|,\left|r_{i j}-T_{l j}\right|\right\}}{\max \left\{\left|\mathrm{B}-T_{u j}\right|,\left|\mathrm{A}-T_{l j}\right|\right\}} & \left(\mathrm{A}<r_{i j}<T_{l j}\right) \text { or }\left(T_{u j}<r_{i j}<\mathrm{B}\right) ; \\ 1 & T_{l j} \leq r_{i j} \leq T_{u j} .\end{cases}
$$

Figure 8 shows schematic of data and normalized values $\left(n_{i j}\right)$ for a criterion with range target. The target range will be somewhere in the universe of data between "A" and " $\mathrm{B}$ ". It means the target range may vary among the extreme values of the range (See Figures 4, 5 and 6). The target can be even a point between the minimum and the maximum values, instead of range. 


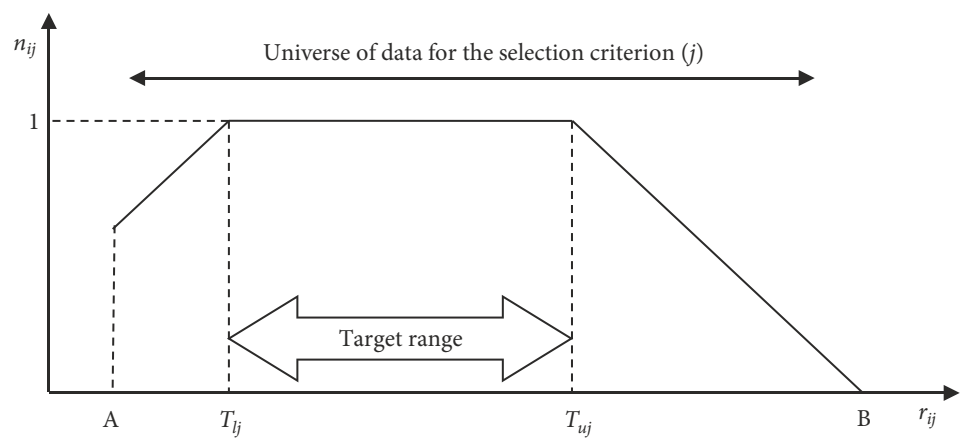

Figure 4. Schematic of normalized values in the proposed method with range target in the middle of data

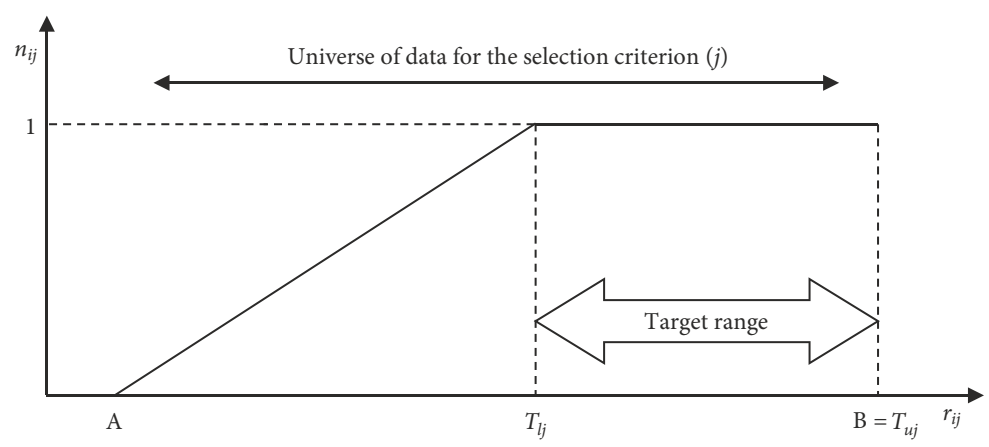

Figure 5. Schematic of normalized values in the proposed method with range target in the upper bound of data

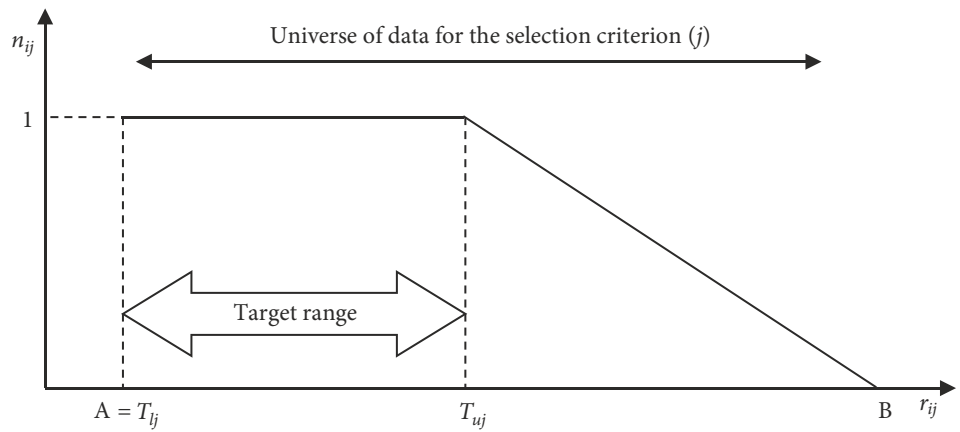

Figure 6. Schematic of normalized values in the proposed method with range target in the lower bound of data

It seems that the proposed method can fulfil all properties described in Figure 1 while overcoming the shortcomings of the available approaches (Perez et al. 2016; Zeng et al. 2013). When a range target criterion changes to a point target criterion, $T_{l j}$ and $T_{u j}$ close together in which $T_{l j}=T_{u j}=T_{j}$. In this case, we obtain Eq. (6) for normalization, thus it is possible to 
affirm this approach, which is extremely similar to Norm (3) in Table 3, which has the most promising structure (see the results described in Section 3.1).

$$
n_{i j}=1-\frac{\left|r_{i j}-T_{j}\right|}{\max \left\{\left|\mathrm{B}-T_{j}\right|,\left|\mathrm{A}-T_{j}\right|\right\}} \text {. }
$$

An efficient approach was presented for the normalization of cost, benefit, and target-based criteria from point to range. This can be used to increase the quality of design decision-making techniques through improving the current widely accepted MADM techniques including COPRAS (Liou et al. 2016), ELECTRE (Figueira et al. 2016), MOORA, EVAMIX, TOPSIS, VIKOR (Mardani et al. 2016), and WASPAS.

\subsection{Extension of WASPAS method with Range Target-Based (WASPAS-RTB) normalization approach}

By considering the matrix presented in Table 1, the following steps are suggested for WASPAS method with range target-based normalization approach (WASPAS-RTB).

Step 1) The decision matrix is normalized using Eq. (7), where the normalized generic element of the decision matrix is denoted by $n_{i j}$. The target range $\left[T_{l j}\right.$, $\left.T_{u j}\right]$ will be somewhere in the universe of data $[\mathrm{A}, \mathrm{B}]$.

$$
n_{i j}= \begin{cases}1-\frac{\min \left\{\left|r_{i j}-T_{u j}\right|,\left|r_{i j}-T_{l j}\right|\right\}}{\max \left\{\left|\mathrm{B}-T_{u j}\right|,\left|\mathrm{A}-T_{l j}\right|\right\}} & \left(\mathrm{A}<r_{i j}<T_{l j}\right) \text { or }\left(T_{u j}<r_{i j}<\mathrm{B}\right) ; \\ 1 & T_{l j} \leq r_{i j} \leq T_{u j} .\end{cases}
$$

When a range target-based criterion changes to a point target-based criterion, $T_{l j}$ and $T_{u j}$ close together in which $T_{l j}=T_{u j}=T_{j}$. The above formula can be also used for cost and benefit criteria. For benefit criteria, target is the maximum value in the universe of data $\left(T_{j}=\right.$ $\mathrm{B})$, and for cost criteria target, it is the minimum value in the universe of data $\left(T_{j}=\mathrm{A}\right)$. It should be noted that in the WASPAS-RTB method, Eq. (7) is applied instead of Eqs. (8 and 9) that were used in the original version of WASPAS method.

For benefit attributes:

For non-benefit attributes:

$$
n_{i j}=\frac{r_{i j}}{\max _{i} r_{i j}}, j=1, \ldots, n ; i=1, \ldots, m .
$$

$$
n_{i j}=\frac{\min _{i} r_{i j}}{r_{i j}}, j=1, \ldots, n ; i=1, \ldots, m .
$$

Step 2) To compute WASPAS-RTB weighted normalized decision matrix, these two actions must be performed. The first one is assigned to the summarization process of WASPAS:

$$
\tilde{x}_{i j, s u m}=\left(n_{i j}{ }^{*} 100\right)^{*} w_{j}, j=1, \ldots, n ; i=1, \ldots, m
$$

and for multiplication part;

$$
\tilde{x}_{i j, \text { mult }}=\left\{\begin{array}{ll}
\left(n_{i j}{ }^{*} 100\right)^{w_{j}} & n_{i j} \neq 0 \\
1 & n_{i j}=0
\end{array}, j=1, \ldots, n ; i=1, \ldots, m .\right.
$$


Given that the normalized values $\left(n_{i j}\right)$ are between zero and one $[0,1]$, multiplication to 100 (Eq. (11)) helps to avoid obtaining less amount for the weighted normalized values $\left(\tilde{x}_{i j, m u l t}\right)$. Furthermore, $\tilde{x}_{i j, m u l t}$ would be 1 (neutral) when $n_{i j}$ is 0 . Multiplication to 100 is also added to Eq. (10) to provide a final result between 0 and 100 in step 3.

Step 3) A joint equation of the weighted aggregation of additive and multiplicative methods to determine the total relative importance of the alternatives was defined as follows:

$$
Q_{i}^{\lambda}=\lambda \sum_{j=1}^{n} \tilde{x}_{i j, s u m}+(1-\lambda) \prod_{j=1}^{n} \tilde{x}_{i j, m u l t}, j=1, \ldots, n ; i=1, \ldots, m .
$$

Finally, the candidate alternatives can be ranked based on the $Q$-values, i.e. the best alternative would be the one having the highest $Q$-value. When the value of $\lambda$ is 0 , the WASPAS method coincides with WPM, while for $\lambda=1$, WASPAS corresponds to WSM.

\section{Results}

\subsection{Analysis of simulation experimental results for the promising Point Target-Based criteria}

Measure of performance, the angle between original data and the normalized one were analyzed using Design Expert software version 7. Table 3 shows the result of analysis of variance (ANOVA), so that the Model F-value of 67.97 implies that the model is significant. There is only a $0.01 \%$ chance that a "Model F-Value" this large could occur due to other reasons.

Table 3. ANOVA results for angle between original data and the normalized values

\begin{tabular}{|l|c|c|c|c|c|}
\hline \multicolumn{1}{|c|}{ Source } & Sum of Squares & Df & Mean Square & F Value & p-value (Prob $>$ F) \\
\hline Model & 131198.6 & 25 & 5247.946 & 67.96762 & $<0.0001$ \\
\hline A-Location of target value & 39608.64 & 2 & 19804.32 & 256.4913 & $<0.0001$ \\
\hline B-Variability & 744.7832 & 1 & 744.7832 & 9.645896 & 0.0021 \\
\hline C-Number of alternatives & 1318.269 & 1 & 1318.269 & 17.07327 & $<0.0001$ \\
\hline D-Normalization method & 44383.59 & 2 & 22191.8 & 287.4122 & $<0.0001$ \\
\hline AB & 16351.76 & 2 & 8175.881 & 105.8881 & $<0.0001$ \\
\hline AC & 127.0686 & 2 & 63.53428 & 0.82285 & 0.4401 \\
\hline AD & 5713.156 & 4 & 1428.289 & 18.49817 & $<0.0001$ \\
\hline BC & 6.708377 & 1 & 6.708377 & 0.086882 & 0.7684 \\
\hline BD & 19760.99 & 2 & 9880.494 & 127.9651 & $<0.0001$ \\
\hline CD & 850.8209 & 2 & 425.4104 & 5.50961 & 0.0044 \\
\hline ABC & 512.8463 & 2 & 256.4231 & 3.321008 & 0.0373 \\
\hline ABD & 1820.012 & 4 & 455.0029 & 5.89287 & 0.0001 \\
\hline Residual & 25788.96 & 334 & 77.21244 & & \\
\hline Lack of Fit & 1212.984 & 10 & 121.2984 & 1.59915 & 0.1055 \\
\hline Pure Error & 24575.97 & 324 & 75.85176 & & \\
\hline
\end{tabular}


Values of "Prob > F" less than 0.05 indicates that the model terms are significant. Therefore, this table is quite revealing in several ways. In this case, $A, B, C, D, A B, A D, B D$, $\mathrm{CD}, \mathrm{ABC}, \mathrm{ABD}$ are significant model terms.

Values greater than 0.1 indicate that the model terms are not significant. Therefore, ACD, BCD, and ABCD were removed. $\mathrm{BC}$ was kept to support hierarchy (ABC).

The "Lack of Fit F-value" of 1.60 implies that the Lack of Fit is not significant relative to the pure error. There is a $10.55 \%$ chance that a "Lack of Fit F-value" this large could occur due to noise. Non-significant lack of fit is good; since we want the model to fit. As shown in Figure 7, when the target value is in the middle of data, the methods present more reasonable outputs (the less is the angle, the better is). However, when there is high variability in the data, the quality of normalization methods is the same for target values between and bigger than data.

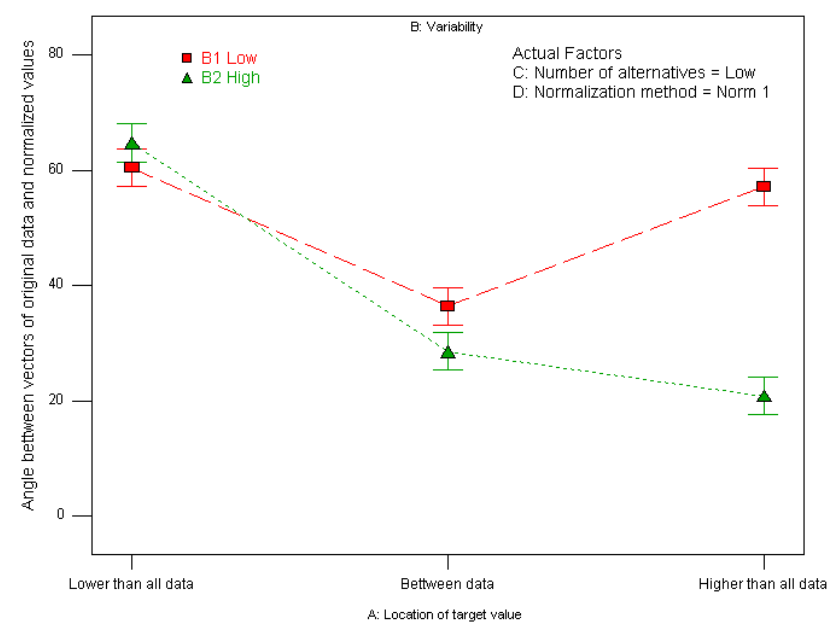

Figure 7. Interaction effects of variability and location of target values on angle between vectors

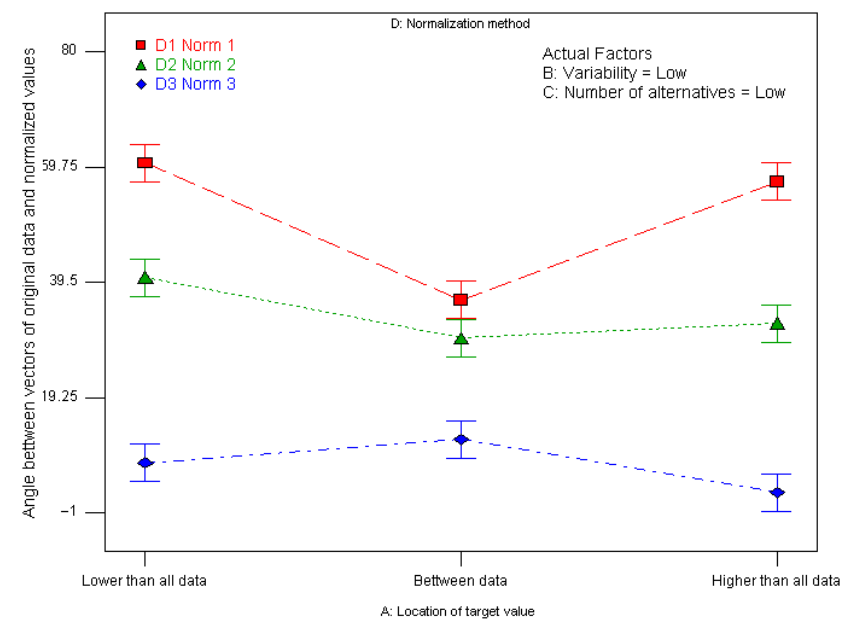

Figure 8. Interaction effects of normalization methods and location of target values on angle between vectors 
Figure 8 shows that Norm 1 is more sensitive to location of target value comparing to the other normalization techniques.

Figure 9 shows that although in Norm 3 the angle between original data and normalized values is less than other methods, the error increases by increasing the variability of data.

Figure 10 reveals, that Norm 3 is not too much sensitive to the number of criteria comparing to other normalization methods.

It seems that normalized values by Norm 3 have less sensitivity to the location of target value, variability of data, and number of alternatives. It can be concluded that Norm 3 has the best structure followed by Norm 2 and Norm 1 due to less sensitivity to the simulation parameters (source of noise variations).

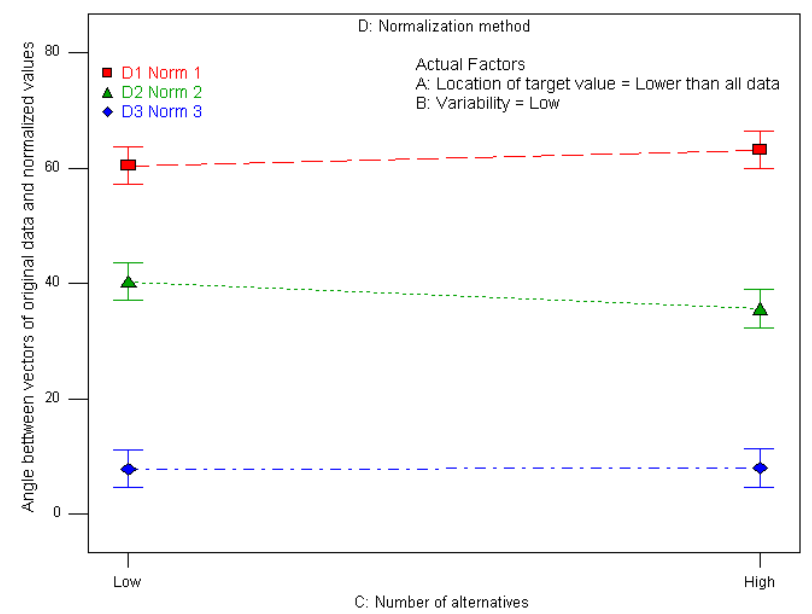

Figure 9. Interaction effects of variability and normalization methods on angle between vectors

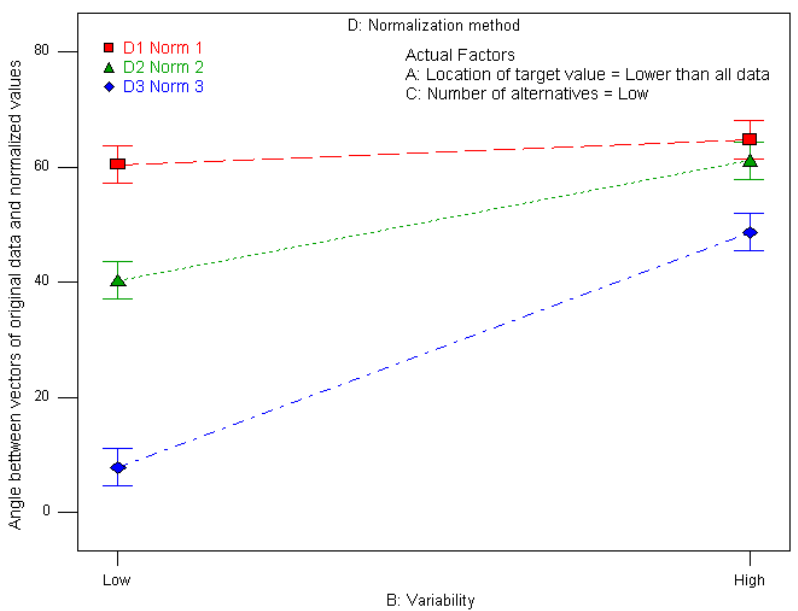

Figure 10. Interaction effects of normalization methods and number of alternatives on angle between vectors 


\subsection{Application of WASPAS-RTB method for protective coating material selection}

This case study deals with the selection of coating material on a substrate made of aluminium alloy (Al-7075, $175 \mathrm{HV}$ ), in order to protect the substrate from the abrasive wear occurred during the sliding movement against a high-strength cast iron $(290 \mathrm{HV})$ counterpart. Figure 11 shows the components schematically in which the aluminium component with its coating moves while the cast iron is stationary. A critical issue is the surface integrity of aluminium substrate with the coating material, while the mating part (i.e. cast iron) undergoes a limited wear. Furthermore, the strength of Al-7075 matrix is an important mechanical characteristic to be preserved and strengthened. Thus, in this application, the choice of material requires constraining by compatibility with other materials. The ceramic particles were used to reinforce the Al-7075 matrix using Cold Spray process (Cavallini et al. 2013).

Appropriate filler hardness can improve the Al-7075substrate resistance to abrasive wear and reduce damaging actions to the integrity of the counterpart made of cast iron. Young's modulus of the filler is influential in load distribution between the components and it should be ascertained that the contribution of filler in the Young's modulus of the cermet $\left(\mathrm{E}_{\mathrm{CM}}\right)$ is such that the $\mathrm{E}_{\mathrm{CM}}$ is close to that of substrate (ES). The Young's modulus of cermet can be gained by the Eq. (13).

$$
\mathrm{E}_{\mathrm{CM}} \propto \mathrm{E}_{\mathrm{m}} \mathrm{v}_{\mathrm{m}}+\mathrm{E}_{\mathrm{f}} \mathrm{v}_{\mathrm{f}} .
$$

Where $\mathrm{E}_{\mathrm{m}}$ signifies the Young's modulus of the Al-7075 matrix, which in this case study is the same as the substrate, $E_{S}$, and $E_{f}$ is the Young's modulus of the filler. The $v_{m}$ and $v_{f}$ stand for the volume fraction of the matrix and the volume fraction of filler, respectively. Another important criterion is the coefficient of thermal expansion (CTE) of filler, which should not cause differential thermal expansion between matrix and reinforcement, and between the cermet and substrate. Thermal conductivity is also considered to protect the Al-7075 substrate from heat. Moreover, the filler should have adequate wettability by the Al-7075 matrix to provide cohesive links with the matrix. In addition to these cases, density, workability and cost are also considered to select the best material. By applying this case study, the capability of WASPAS-RTB approach to explicitly address the target criteria is demonstrated. Here, approximately $40 \%$ of the attributes are point and range target-based, and the rest are cost and benefit criteria. This implies the importance of this class of criteria in the MADM algorithm.

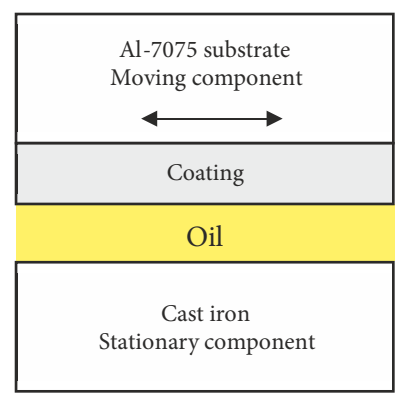

Figure 11. Schematic of the wear couple: protective coating material selection 
A set of candidate materials that can be used to make filler to reinforce the Al-7075 matrix is listed in Table 4, which include $\mathrm{Al}_{2} \mathrm{O}_{3}$ (94\% purity), TiN (99\% purity), TiC (99\% purity), $\mathrm{TiO}_{2}$ (99\% purity), $\mathrm{SiC}$ (99\% purity), $\mathrm{SiN}$ (99\% purity), WC (99\% purity), CrN (99\% purity), AlN (99\% purity). In addition to the list of the materials, Table 4 shows the importance of selection criteria (weights) and the technical data regarding the candidate materials for the required criteria.

Table 5 shows the normalized decision-making matrix. The normalized values were obtained from Eq. (7). Tables 6 and 7 present the weighted normalized decision matrix that was respectively calculated according to Eqs (10 and 11). Table 8 presents three criteria of optimality, which are calculated according to Eq. (12), where $\lambda=0.5$. There is a good agreement between $Q_{i}^{(1)}$ and $Q_{i}^{(2)}$, and this can contribute to verifying the extended WASPASRTB method.

As shown in Table $8, \mathrm{TiO}_{2}$ is the best option based on WASPAS-RTB method. There are considerable similarities between the obtained results and the ranking is calculated according to C-VIKOR method (Cavallini et al. 2013). However, the first choice in these two methods is different. In addition to the dissimilarity of the used algorithms, there is a slight change in the input data. In this study, criterion of filler Young's modulus, extended from point target to range target to is used to demonstrate the capabilities of the proposed method. C-VIKOR recommended materials to designers as $\mathrm{Al} 2 \mathrm{O} 3>\mathrm{TiO} 2>\mathrm{SiC}>\mathrm{SiN}>\mathrm{CrN}>\mathrm{WC}>\mathrm{TiN}>\mathrm{TiC}>$ AlN. Target value for the criterion of filler Young's modulus was $300 \mathrm{GPa}$, while range target value was considered from 200 to $300 \mathrm{GPa}$.

Table 4. Material selection for protective coating on an aluminium alloy substrate

\begin{tabular}{|l|c|c|c|c|c|c|c|c|}
\hline & $\begin{array}{c}\text { Filler } \\
\text { hardness } \\
(\mathrm{HV})\end{array}$ & $\begin{array}{c}\text { Filler } \\
\text { Young's } \\
\text { Modulus } \\
(\mathrm{GPa})\end{array}$ & $\begin{array}{c}\text { Filler } \\
\mathrm{CTE} \\
\left(10^{-6} /{ }^{\circ} \mathrm{C}\right)\end{array}$ & $\begin{array}{c}\text { Filler } \\
\text { density } \\
(\mathrm{gr} / \mathrm{cc})\end{array}$ & $\begin{array}{c}\text { Filler } \\
\text { thermal } \\
\text { conductivity } \\
(\mathrm{W} / \mathrm{m} \mathrm{K})\end{array}$ & $\begin{array}{c}\text { Wetta- } \\
\text { bility } \\
(\text { null })\end{array}$ & $\begin{array}{c}\text { Work- } \\
\text { ability } \\
{[\text { null }]}\end{array}$ & $\begin{array}{c}\text { Cost } \\
(€ / \mathrm{kg})\end{array}$ \\
\hline $\begin{array}{l}\text { Objective } \\
\text { type }\end{array}$ & Point target & $\begin{array}{c}\text { Range } \\
\text { target }\end{array}$ & $\begin{array}{c}\text { Point } \\
\text { target }\end{array}$ & Min & Max & Max & Max & Min \\
\hline $\begin{array}{l}\text { Universe } \\
\text { of data } \\
{[\mathrm{A}, \mathrm{B}]}\end{array}$ & {$[1100,2900]$} & {$[300,720]$} & {$[2.3,23]$} & {$[3.1,15.72]$} & {$[11.7,160]$} & {$[2,5]$} & {$[1,3]$} & {$[8.5,100]$} \\
\hline $\begin{array}{l}\text { Target } \\
{\left[T_{l j}, T_{u j}\right]}\end{array}$ & {$[1100,1100]$} & {$[200,300]$} & {$[23,23]$} & {$[3.1,3.1]$} & {$[160,160]$} & {$[5,5]$} & {$[3,3]$} & {$[8.5,8.5]$} \\
\hline $\mathrm{Al}{ }_{2} \mathrm{O}_{3}$ & 1175 & 300 & 8.1 & 3.69 & 18 & 5 & 3 & 8.5 \\
\hline $\mathrm{TiN}$ & 2500 & 600 & 9.4 & 5.22 & 19.25 & 4 & 1 & 38 \\
\hline $\mathrm{TiC}$ & 2900 & 439 & 8.3 & 4.94 & 20 & 2 & 1 & 40 \\
\hline $\mathrm{TiO}{ }_{2}$ & 1100 & 230 & 9 & 4.25 & 11.7 & 4 & 3 & 22 \\
\hline $\mathrm{SiC}$ & 2800 & 410 & 4 & 3.1 & 120 & 2 & 1 & 13 \\
\hline $\mathrm{SiN}$ & 1580 & 310 & 3.3 & 3.3 & 30 & 4 & 2 & 33 \\
\hline $\mathrm{WC}$ & 2300 & 720 & 3.8 & 15.72 & 84.82 & 2 & 1 & 17 \\
\hline $\mathrm{CrN}$ & 1100 & 400 & 2.3 & 6 & 19.2 & 4 & 3 & 100 \\
\hline $\mathrm{AlN}$ & 1100 & 330 & 4.5 & 3.26 & 160 & 4 & 3 & 100 \\
\hline $\mathrm{Weight}$ & 0.184 & 0.172 & 0.172 & 0.043 & 0.086 & 0.064 & 0.086 & 0.193 \\
\hline
\end{tabular}


Table 5. Normalized decision-making matrix

\begin{tabular}{|l|c|c|c|c|c|c|c|c|}
\hline & $\begin{array}{c}\text { Filler } \\
\text { hardness } \\
(\mathrm{HV})\end{array}$ & $\begin{array}{c}\text { Filler } \\
\text { Young's } \\
\text { Modulus } \\
(\mathrm{GPa})\end{array}$ & $\begin{array}{c}\text { Filler } \\
\mathrm{CTE} \\
\left(10^{-6} /{ }^{\circ} \mathrm{C}\right)\end{array}$ & $\begin{array}{c}\text { Filler } \\
\text { density } \\
(\mathrm{gr} / \mathrm{cc})\end{array}$ & $\begin{array}{c}\text { Filler } \\
\text { thermal } \\
\text { conduc- } \\
\text { tivity } \\
(\mathrm{W} / \mathrm{m} \mathrm{K})\end{array}$ & $\begin{array}{c}\text { Wettability } \\
(\text { null })\end{array}$ & $\begin{array}{c}\text { Workability } \\
{[\text { null }]}\end{array}$ & $\begin{array}{c}\text { Cost } \\
(€ / \mathrm{kg})\end{array}$ \\
\hline $\begin{array}{l}\text { Objective } \\
\text { type }\end{array}$ & $\begin{array}{c}\text { Point } \\
\text { target }\end{array}$ & $\begin{array}{c}\text { Range } \\
\text { target }\end{array}$ & $\begin{array}{c}\text { Point } \\
\text { target }\end{array}$ & Min & Max & Max & Max & Min \\
\hline $\mathrm{Al}_{2} \mathrm{O}_{3}$ & 9.583 & 100.000 & 28.019 & 95.325 & 4.248 & 100.000 & 100.000 & 100.000 \\
\hline $\mathrm{TiN}$ & 2.222 & 28.571 & 34.300 & 83.201 & 5.091 & 66.667 & 0.000 & 67.760 \\
\hline $\mathrm{TiC}$ & 0.000 & 66.905 & 28.986 & 85.420 & 5.597 & 0.000 & 0.000 & 65.574 \\
\hline $\mathrm{TiO}{ }_{2}$ & 100.000 & 100.000 & 32.367 & 90.887 & 0.000 & 66.667 & 100.000 & 85.246 \\
\hline $\mathrm{SiC}$ & 0.556 & 73.810 & 8.213 & 100.000 & 73.028 & 0.000 & 0.000 & 95.082 \\
\hline $\mathrm{SiN}$ & 7.333 & 97.619 & 4.831 & 98.415 & 12.340 & 66.667 & 50.000 & 73.224 \\
\hline $\mathrm{WC}$ & 3.333 & 0.000 & 7.246 & 0.000 & 49.305 & 0.000 & 0.000 & 90.710 \\
\hline $\mathrm{CrN}$ & 100.000 & 76.190 & 0.000 & 77.021 & 5.057 & 66.667 & 100.000 & 0.000 \\
\hline $\mathrm{AlN}$ & 100.000 & 92.857 & 10.628 & 98.732 & 100.000 & 66.667 & 100.000 & 0.000 \\
\hline
\end{tabular}

Table 6. Weighted normalized decision matrix: Summation $\left(\tilde{x}_{i j, s u m}\right)$

\begin{tabular}{|l|c|c|c|c|c|c|c|c|}
\hline & $\begin{array}{c}\text { Filler } \\
\text { hardness } \\
(\mathrm{HV})\end{array}$ & $\begin{array}{c}\text { Filler } \\
\text { Young's } \\
\text { Modulus } \\
(\mathrm{GPa})\end{array}$ & $\begin{array}{c}\text { Filler } \\
\mathrm{CTE} \\
\left(10^{-6} /{ }^{\circ} \mathrm{C}\right)\end{array}$ & $\begin{array}{c}\text { Filler } \\
\text { density } \\
(\mathrm{gr} / \mathrm{cc})\end{array}$ & $\begin{array}{c}\text { Filler } \\
\text { thermal } \\
\text { conduc- } \\
\text { tivity } \\
(\mathrm{W} / \mathrm{m} \mathrm{K})\end{array}$ & $\begin{array}{c}\text { Wettability } \\
(\text { null })\end{array}$ & $\begin{array}{c}\text { Workability } \\
\text { [null] }\end{array}$ & $\begin{array}{c}\text { Cost } \\
(€ / \mathrm{kg})\end{array}$ \\
\hline $\mathrm{Al}_{2} \mathrm{O}_{3}$ & 1.763 & 17.200 & 4.819 & 4.099 & 0.365 & 6.400 & 8.600 & 19.300 \\
\hline $\mathrm{TiN}$ & 0.409 & 4.914 & 5.900 & 3.578 & 0.438 & 4.267 & 0.000 & 13.078 \\
\hline $\mathrm{TiC}$ & 0.000 & 11.508 & 4.986 & 3.673 & 0.481 & 0.000 & 0.000 & 12.656 \\
\hline $\mathrm{TiO}_{2}$ & 18.400 & 17.200 & 5.567 & 3.908 & 0.000 & 4.267 & 8.600 & 16.452 \\
\hline $\mathrm{SiC}$ & 0.102 & 12.695 & 1.413 & 4.300 & 6.280 & 0.000 & 0.000 & 18.351 \\
\hline $\mathrm{SiN}$ & 1.349 & 16.790 & 0.831 & 4.232 & 1.061 & 4.267 & 4.300 & 14.132 \\
\hline $\mathrm{WC}$ & 0.613 & 0.000 & 1.246 & 0.000 & 4.240 & 0.000 & 0.000 & 17.507 \\
\hline $\mathrm{CrN}$ & 18.400 & 13.105 & 0.000 & 3.312 & 0.435 & 4.267 & 8.600 & 0.000 \\
\hline $\mathrm{AlN}$ & 18.400 & 15.971 & 1.828 & 4.245 & 8.600 & 4.267 & 8.600 & 0.000 \\
\hline
\end{tabular}

As indicated by the ranking order, $\mathrm{TiO} 2$ and $\mathrm{Al} 2 \mathrm{O} 3$ are the first and second ranked materials. This can be mainly due to their hardness, Young's modulus, coefficient of thermal expansion, and wettability as well as workability. The hardness values of these materials are much lower than WC, SiC, TiC and TiN. However, high hardness is preferable to avoid wear, so that materials with extremely high hardness suffer from brittleness. In addition, their wettability is also better than carbide ceramics, which contributes to the articulation and reduction of wear. The moduli of these materials are closer to those of substrate rather than the other alternatives. This contributes to more uniform stress distribution and load transfer 
Table 7. Weighted normalized decision matrix: Multiplication $\left(\tilde{x}_{i j, m u l t}\right)$

\begin{tabular}{|l|c|c|c|c|c|c|c|c|}
\hline & $\begin{array}{c}\text { Filler } \\
\text { hardness } \\
(\mathrm{HV})\end{array}$ & $\begin{array}{c}\text { Filler } \\
\text { Young's } \\
\text { Modulus } \\
(\mathrm{GPa})\end{array}$ & $\begin{array}{c}\text { Filler } \\
\mathrm{CTE} \\
\left(10^{-6} /{ }^{\circ} \mathrm{C}\right)\end{array}$ & $\begin{array}{c}\text { Filler } \\
\text { density } \\
(\mathrm{gr} / \mathrm{cc})\end{array}$ & $\begin{array}{c}\text { Filler } \\
\text { thermal } \\
\text { conduc- } \\
\text { tivity } \\
(\mathrm{W} / \mathrm{m} \text { K) }\end{array}$ & $\begin{array}{c}\text { Wettability } \\
(\text { null })\end{array}$ & $\begin{array}{c}\text { Workability } \\
\text { [null] }\end{array}$ & $\begin{array}{c}\text { Cost } \\
(€ / \mathrm{kg})\end{array}$ \\
\hline $\mathrm{Al}_{2} \mathrm{O}_{3}$ & 1.516 & 2.208 & 1.774 & 1.216 & 1.132 & 1.343 & 1.486 & 2.432 \\
\hline $\mathrm{TiN}$ & 1.158 & 1.780 & 1.837 & 1.209 & 1.150 & 1.308 & 1.000 & 2.256 \\
\hline $\mathrm{TiC}$ & 1.000 & 2.061 & 1.784 & 1.211 & 1.160 & 1.000 & 1.000 & 2.242 \\
\hline $\mathrm{TiO}_{2}$ & 2.333 & 2.208 & 1.819 & 1.214 & 1.000 & 1.308 & 1.486 & 2.358 \\
\hline $\mathrm{SiC}$ & 0.897 & 2.096 & 1.436 & 1.219 & 1.446 & 1.000 & 1.000 & 2.409 \\
\hline $\mathrm{SiN}$ & 1.443 & 2.199 & 1.311 & 1.218 & 1.241 & 1.308 & 1.400 & 2.290 \\
\hline $\mathrm{WC}$ & 1.248 & 1.000 & 1.406 & 1.000 & 1.398 & 1.000 & 1.000 & 2.387 \\
\hline $\mathrm{CrN}$ & 2.333 & 2.107 & 1.000 & 1.205 & 1.150 & 1.308 & 1.486 & 1.000 \\
\hline $\mathrm{AlN}$ & 2.333 & 2.180 & 1.502 & 1.218 & 1.486 & 1.308 & 1.486 & 1.000 \\
\hline
\end{tabular}

between the components. Meanwhile, the CTEs of both $\mathrm{TiO} 2$ and $\mathrm{Al} 2 \mathrm{O} 3$ are higher than the other materials except for TiN, so that provide smaller difference in thermal expansion and reduce the risk of thermal cracks. These properties make them suitable for using as filler materials in this application. On the other hand, tungsten carbide as the last ranked material is extremely hard and stiff (hardness of $2300 \mathrm{HV}$ and modulus of $720 \mathrm{GPa}$ ) with limited workability and machinability. Meanwhile, WC has high density and extremely low CTE.

Table 8 . Three criteria of optimality

\begin{tabular}{|l|c|c|c|c|}
\hline & $Q_{i}^{(1)}$ & $Q_{i}^{(2)}$ & $Q_{i}$ & Raking \\
\hline $\mathrm{Al}_{2} \mathrm{O}_{3}$ & 62.547 & 39.691 & 51.119 & 2 \\
\hline $\mathrm{TiN}$ & 32.582 & 15.551 & 24.067 & 7 \\
\hline $\mathrm{TiC}$ & 33.303 & 11.574 & 22.439 & 8 \\
\hline $\mathrm{TiO}_{2}$ & 74.394 & 52.156 & 63.275 & 1 \\
\hline $\mathrm{SiC}$ & 43.141 & 11.473 & 27.307 & 6 \\
\hline $\mathrm{SiN}$ & 46.963 & 26.384 & 36.673 & 4 \\
\hline $\mathrm{WC}$ & 23.607 & 5.856 & 14.731 & 9 \\
\hline $\mathrm{CrN}$ & 48.118 & 13.246 & 30.682 & 5 \\
\hline $\mathrm{AlN}$ & 61.912 & 26.885 & 44.398 & 3 \\
\hline
\end{tabular}

\section{Discussion}

There is a need to study the strengths and weaknesses of different decision-making methods (Zavadskas et al. 2014c). Many decision methods developed for engineering design have neglected a number of specific elements that should be taken into account for materials and design selection problems. 


\subsection{Discussion of effectiveness of the new method}

To make dimensionless methods applied and accepted more widely in design decision-making problems, from materials to civil engineering, as well as other applications of MADM such as medical decision-making problems, extensions to model architectures for problem settings are needed. Despite all progress made in the development of different target-based dimensionless methods, there is no definite answer to question: which technique is the most appropriate one? The sensitivity analysis of promising target-based normalization methods was conducted in the presence of finite changes in one or more of the decision matrix parameters. Although, it is hardly possible to evaluate the effect of various methods of normalization of a decision-making matrix on the obtained numerical results. This research attempted to compare the effectiveness of three promising techniques. Monte Carlo simulation method was applied for the generation of the attribute values. Simulation parameters were the number of alternatives, distribution of data, and locations of target criteria. It was shown that the dimensionless method with Linear-max-min structure (Norm (3)) is more appropriate than "Non-monotonic normalization" and "Comprehensive normalization method" (Norms (1), and (2)) due to less sensitivity to the source of noise variations/simulation parameters. Although, it has been attempted to generate realistic data, for simulation, based on material selection environment, the results on the comparison of target-based normalization methods might not be extendable to all data ranges of different problems.

It was revealed that, for the range target-based criteria, the suggested method can overcome the shortcomings of available techniques. The proposed normalization approach that applied for WASPAS method, can provide acceptable results from the view point of symmetry in the normalized values for the same data, when criteria type is either "cost", or "benefit". For example, in the criterion of thermal conductivity, and based on the data presented in Table 4, Figure 12 demonstrates the symmetry of normalized values using the proposed normalization method. It is worth noting that most of dimensionless methods suffer from asymmetry issue (Jahan, Edwards 2015).

The ranking orders of alternatives in the proposed WASPAS-RTB method will not be affected by adding or removing options, while this issue (Rank Reversal) weakens most of MADM methods. Negative values are also converted to positive values using the new

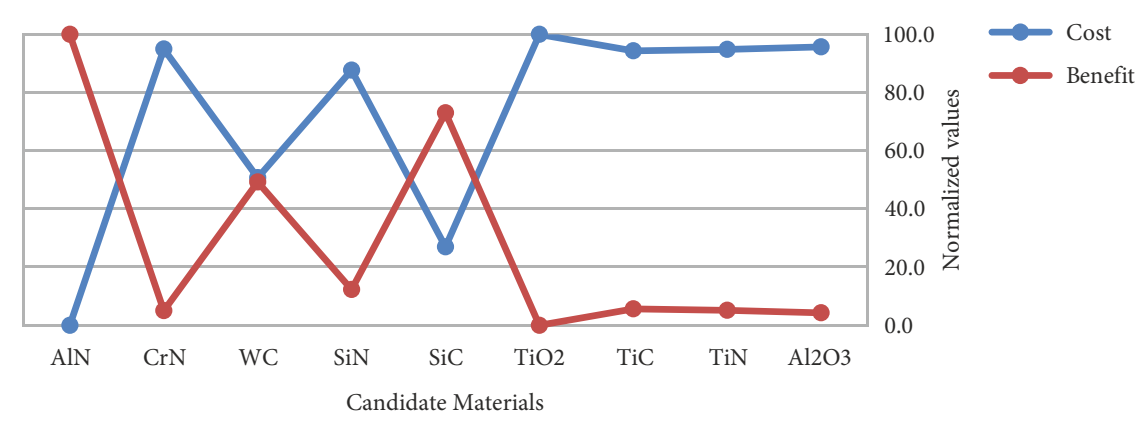

Figure 12. Symmetry of normalized values by the proposed normalization method: Criterion of thermal conductivity considered one time as "cost" type and then as "benefit" 
approach. Totally, all expected properties from the viewpoint of normalizing process were covered. The generalizability of these results, however, may subject to some limitations. For instance, it might not be possible to apply the proposed normalization method to all MADM problems and also use the extended approach (WASPAS-RTB) to all decision-making problems.

\subsection{Discussion on material selection for robust design}

During the past decades, there was a great focus on product improvement through manufacturing methods, while the emphasis of recent efforts has now moved upstream, such as refining the materials and design. The importance of Quality Function Deployment (QFD) in design process has been emphasized in the literature (Liu 2011), since it can facilitate the identification of preliminary target values in both material and design by taking the customer's voice into account. On the other hand, meeting continuous growing of customer expectations needs innovative designs at lower prices, and faster response times. Designers must be able to either anticipate changes in customer requirements that may occur during the product development process or provide additional design flexibility. It seems that the latter is more practical. Although, recently, the role of QFD in material selection was described (Jahan et al. 2016; Prasad, Chakraborty 2013), it has not been well tied with practical material selection in this regard.

Material selection is usually conducted in the early stages of design. Decisions made during this phase are often difficult due to the uncertainty caused by the lack of objective data. However, material selection criteria should be as specific as the design definition will allow. Early in design, the criteria might be "must be transparent", "should be easily manufactured", "must be tough," or "must have low specific modulus". During configuration design, the criteria might be "toughness exceeding $60 \mathrm{MPa}$ ", "electrical conductivity between 0.1 and $0.4 \mu \Omega$ ". Designers, may have some knowledge of the range of these design requirements, but may not be clear as to the exact targets that should be met. Range target helps to readily adaptable, and changing customer requirements, which are also particularly important for robust design. According to (Arvidsson, Gremyr 2008), robust design methodology means "systematic efforts to achieve insensitivity to noise factors [so that] these efforts are based on an awareness of variation and are applicable in all stages of product design". Although many useful statistical tools available for creating robust designs, there is limited attention and even no official introduced technique to consider the concepts of robust design in materials selection stage. The literature emphasizing the more mathematical modelling and predictive aspects of subject, while the author emphasizes how the application of extended decision-making tool provides an opportunity to have flexible design. The connection of material selection with the quality engineering concepts, robust design in particular, on the head of MCDM has not well discovered yet, and more work remains to make an integrated fully robust design methodology. 


\section{Conclusions}

Different MADM approaches are the results of diverse aggregation, weighing and normalization methods. Normalization is a foundation of a rational decision in engineering design problems, and it must cover target-based criteria from point to range, in addition to cost and benefit criteria that are used in other selection problems. During the early stages of product design, from conceptual design selection to choice of materials, when little is known concerning the design requirements, it is desirable to allow the target design parameters/material properties vary within a certain range rather than setting point targets. In this manner, designs are more flexible in the later stages and can be readily adapted to changing design requirements allowing companies to respond more quickly and at lower costs than their competitors. This verifies the need to update well-accepted MADM methods in this regard. In this paper, at the first stage, the best formula structure of normalization for target-based criteria was selected from promising methods through numerical simulation. Then, the selected one was extended to overcome the shortcomings of available methods. The developed range target-based normalization method was applied in WASPAS technique, and the method was adjusted accordingly. The capability of WASPAS-RTB method in dealing with all types of criteria was demonstrated using a material selection case study. However, the promises of the proposed normalization methods as well as the developed WASPAS technique will be fulfilled only when practical research progress is achieved by implementing the best decisions. Further studies regarding the role of promising normalization methods on increasing quality of MADM methods would be interesting.

\section{Acknowledgements}

This research project was supported by Islamic Azad University, Semnan Branch, with Grant no. 4046, and the author would like to show his grateful thanks for the close cooperation.

\section{References}

Adan, O. C.; Ng-a-Tham, J.; Hanke, W.; Sigsgaard, T.; Van Den Hazel, P.; Wu, F. 2007. In search of a common European approach to a healthy indoor environment, Environmental health perspectives 115(6): 983-988. https://doi.org/10.1289/ehp.8991

Al-Oqla, F. M.; Sapuan, S. 2016. Polymer selection approach for commonly and uncommonly used natural fibers under uncertainty environments, JOM 67(10): 2450-2463.

https://doi.org/10.1007/s11837-015-1548-8

Al-Oqla, F. M.; Sapuan, S.; Ishak, M. R.; Nuraini, A. 2016. A decision-making model for selecting the most appropriate natural fiber-Polypropylene-based composites for automotive applications, Journal of Composite Materials 50(4): 543-556. https://doi.org/10.1177/0021998315577233

Alemi-Ardakani, M.; Milani, A.; Yannacopoulos, S.; Shokouhi, G. 2015. A multicriteria experimental analysis of impact on fiber reinforced polymer composite laminates, Materials Today Communications 4: 6-15. https://doi.org/10.1016/j.mtcomm.2015.02.001 
Alemi-Ardakani, M.; Milani, A. S.; Yannacopoulos, S.; Shokouhi, G. 2016. On the effect of subjective, objective and combinative weighting in multiple criteria decision making: a case study on impact optimization of composites, Expert Systems With Applications 46: 426-438.

https://doi.org/10.1016/j.eswa.2015.11.003

Ardeshirilajimi, A.; Aghanouri, A.; Abedian, A.; Milani, A. 2015. An exponential placement method for materials selection, The International Journal of Advanced Manufacturing Technology 78(1-4): 641-650. https://doi.org/10.1007/s00170-014-6582-0

Arvidsson, M.; Gremyr, I. 2008. Principles of robust design methodology, Quality and Reliability Engineering International 24(1): 23-35. https://doi.org/10.1002/qre.864

Ashby, M. F. 1989. Materials selection in conceptual design, Materials Science and Technology 5(6): 517-525. https://doi.org/10.1179/mst.1989.5.6.517

Ashby, M. F. 2000. Multi-objective optimization in material design and selection, Acta Materialia 48(1): 359-369. https://doi.org/10.1016/S1359-6454(99)00304-3

Ashby, M. F.; Brechet, Y. J. M.; Cebon, D.; Salvo, L. 2004. Selection strategies for materials and processes, Materials and Design 25(1): 51-67. https://doi.org/10.1016/S0261-3069(03)00159-6

Bahraminasab, M.; Jahan, A. 2011. Material selection for femoral component of total knee replacement using comprehensive VIKOR, Materials \& Design 32: 4471-4477.

https://doi.org/10.1016/j.matdes.2011.03.046

Barzilai, J. ; Golany, B. 1994. AHP rank reversal, normalization and aggregation rules, Infor-Information Systems and Operational Research 32(2): 57-64. https://doi.org/10.1080/03155986.1994.11732238

Brifcani, N.; Day, R.; Walker, D.; Hughes, S.; Ball, K. ; Price, D. 2012. A review of cutting-edge techniques for material selection, in 2nd international conference on advanced composite materials and technologies for aerospace applications, 11-13 June 2012, Wrexham, UK, 58-64.

Cavallini, C.; Giorgetti, A.; Citti, P.; Nicolaie, F. 2013. Integral aided method for material selection based on quality function deployment and comprehensive VIKOR algorithm, Materials \& Design 47: 27-34. https://doi.org/10.1016/j.matdes.2012.12.009

Celen, A. 2014. Comparative analysis of normalization procedures in TOPSIS method: with an application to Turkish deposit banking market, Informatica 25(2): 185-208. https://doi.org/10.15388/Informatica.2014.10

Chakraborty, S.; Zavadskas, E. K. 2014. Applications of WASPAS method in manufacturing decision making, Informatica 25(1): 1-20. https://doi.org/10.15388/Informatica.2014.01

Chatterjee, P.; Athawale, V. M.; Chakraborty, S. 2011. Materials selection using complex proportional assessment and evaluation of mixed data methods, Materials \& Design 32: 851-860. https://doi.org/10.15388/Informatica.2014.01

Dejus, T. ; Antucheviciene, J. 2013. Assessment of health and safety solutions at a construction site, Journal of Civil Engineering and Management 19: 728-737. https://doi.org/10.3846/13923730.2013.812578

Deng, H. 2007. A similarity-based approach to ranking multicriteria alternatives, in Advanced intelligent computing theories and applications. With aspects of artificial intelligence. Springer.

Edwards, K. L. 2004. Strategic substitution of new materials for old: applications in automotive product development, Materials \& Design 25(6): 529-533. https://doi.org/10.1016/j.matdes.2003.12.008

Edwards, K. L. 2005. Selecting materials for optimum use in engineering components, Materials and Design 26(5): 469-473. https://doi.org/10.1016/j.matdes.2004.07.004

Edwards, K. L.; Deng, Y. M. 2007. Supporting design decision-making when applying materials in combination, Materials and Design 28(4): 1288-1297. https://doi.org/10.1016/j.matdes.2005.12.009 
Farag, M. M. 2008. Quantitative methods of materials substitution: application to automotive components, Materials and Design 29(2): 374-380. https://doi.org/10.1016/j.matdes.2007.01.028

Farag, M. M. 2013. Materials and process selection for engineering design. CRC Press. https://doi.org/10.1201/b16047

Figueira, J. R.; Mousseau, V.; Roy, B. 2016. ELECTRE Methods, in S. Greco, M. Ehrgott, R. J. Figueira (Eds.). Multiple criteria decision analysis: state of the art surveys. New York, NY: Springer New York. https://doi.org/10.1007/978-1-4939-3094-4_5

Ghorshi Nezhad, M. R.; Zolfani, S. H.; Moztarzadeh, F.; Zavadskas, E. K. ; Bahrami, M. 2015. Planning the priority of high tech industries based on SWARA-WASPAS methodology: the case of the nanotechnology industry in Iran, Economic Research-Ekonomska Istrazivanja 28(1): 1111-1137. https://doi.org/10.1080/1331677X.2015.1102404

Hafezalkotob, A.; Hafezalkotob, A. 2016. Risk-based material selection process supported on information theory: a case study on industrial gas turbine, Applied Soft Computing 52: 1116-1129. https://doi.org/10.1016/j.asoc.2016.09.018

Hafezalkotob, A.; Hafezalkotob, A.; Sayadi, M. K. 2016a. Extension of MULTIMOORA method with interval numbers: an application in materials selection, Applied Mathematical Modelling 40(2): 1372-1386. https://doi.org/10.1016/j.apm.2015.07.019

Hafezalkotob, A.; Hafezalkotob, A.; Sayadi, M. K. 2016b. Extension of MULTIMOORA method with interval numbers: an application in materials selection, Applied Mathematical Modelling 40(2): 1372-1386. https://doi.org/10.1016/j.apm.2015.07.019

Ishak, N. M.; Malingam, S. D.; Mansor, M. R. 2016. Selection of natural fibre reinforced composites using fuzzy VIKOR for car front hood, International Journal of Materials and Product Technology 53(3-4): 267-285. https://doi.org/10.1504/IJMPT.2016.079205

Jahan, A.; Bahraminasab, M.; Edwards, K. L. 2012. A target-based normalization technique for materials selection, Materials \& Design 35: 647-654. https://doi.org/10.1016/j.matdes.2011.09.005

Jahan, A.; Edwards, K. L. 2015. A state-of-the-art survey on the influence of normalization techniques in ranking: improving the materials selection process in engineering design, Materials \& Design 65: 335-342. https://doi.org/10.1016/j.matdes.2014.09.022

Jahan, A.; Edwards, K. L.; Bahraminasab, M. 2016. Multi-criteria decision analysis for supporting the selection of engineering materials in product design. Oxford, Butterworth-Heinemann.

Jahan, A.; Ismail, M. Y.; Sapuan, S. M.; Mustapha, F. 2010. Material screening and choosing methods - a review, Materials \& Design 31(2): 696-705. https://doi.org/10.1016/j.matdes.2009.08.013

Jahan, A.; Mustapha, F.; Ismail, M. Y.; Sapuan, S. M.; Bahraminasab, M. 2011. A comprehensive VIKOR method for material selection, Materials \& Design 32(3): 1215-1221.

https://doi.org/10.1016/j.matdes.2010.10.015

Kabir, G.; Lizu, A. 2016. Material selection for femoral component of total knee replacement integrating fuzzy AHP with PROMETHEE, Journal of Intelligent and Fuzzy Systems 30(6): 3481-3493. https://doi.org/10.3233/IFS-162094

Liou, J. J. H.; Tamošaitienè, J.; Zavadskas, E. K.; Tzeng, G.-H. 2016. New hybrid COPRAS-G MADM Model for improving and selecting suppliers in green supply chain management, International Journal of Production Research 54(1): 114-134. https://doi.org/10.1080/00207543.2015.1010747

Liu, H.-T. 2011. Product design and selection using fuzzy QFD and fuzzy MCDM approaches, Applied Mathematical Modelling 35(1): 482-496. https://doi.org/10.1016/j.apm.2010.07.014

Mardani, A.; Zavadskas, E. K.; Govindan, K.; Amat Senin, A.; Jusoh, A. 2016. VIKOR technique: a systematic review of the state of the art literature on methodologies and applications, Sustainability 8(1): 1-37. https://doi.org/10.3390/su8010037 
Mastura, M.; Sapuan, S.; Mansor, M.; Nuraini, A. 2016. Environmentally conscious hybrid bio-composite material selection for automotive anti-roll bar, The International Journal of Advanced Manufacturing Technology 89(5-8): 2203-2219. https://doi.org/10.1007/s00170-016-9217-9

Milani, A. S.; Shanian, A.; Madoliat, R.; Nemes, J. A. 2005. The effect of normalization norms in multiple attribute decision making models: a case study in gear material selection, Structural and Multidisciplinary Optimization 29(4): 312-318. https://doi.org/10.1007/s00158-004-0473-1

Nayak, S.; Misra, B.; Behera, H. 2014. Impact of data normalization on stock index forecasting, International Journal of Computer Information Systems and Industrial Management Applications 6: 257-269.

Opricovic, S.; Tzeng, G. H. 2004. Compromise solution by MCDM methods: a comparative analysis of VIKOR and TOPSIS, European Journal of Operational Research 156(2): 445-455. https://doi.org/10.1016/S0377-2217(03)00020-1

Peldschus, F. 2008. Experience of the game theory application in construction management, Technological and Economic Development of Economy 14(4): 531-545. https://doi.org/10.3846/1392-8619.2008.14.531-545

Perez, E. C.; Lamata, M.; Verdegay, J. 2016. RIM-Reference Ideal Method in Multicriteria Decision Making, Information Sciences 337-338: 1-10.

Prasad, K.; Chakraborty, S. 2013. A quality function deployment-based model for materials selection, Materials \& Design 49: 525-535. https://doi.org/10.1016/j.matdes.2013.01.035

Sapuan, S. M.; Mujtaba, I. M.; Wright, C. S. 2009. State of the art review of engineering materials selection methods, Multidiscipline Modeling in Materials and Structures 3(5): 263-268. https://doi.org/10.1108/15736105200900021

Shan, M. M.; You, J. X.; Liu, H. C. 2016. Some Interval 2-Tuple linguistic harmonic mean operators and their application in material selection, Advances in Materials Science and Engineering. Article ID 7034938, 1-13. https://doi.org/10.1155/2016/7034938

Shih, H. S.; Shyur, H. J.; Lee, E. S. 2007. An extension of TOPSIS for group decision making, Mathematical and Computer Modelling 45(7-8): 801-813. https://doi.org/10.1016/j.mcm.2006.03.023

Sirisalee, P.; Ashby, M. F.; Parks, G. T.; Clarkson, P. J. 2004. Multi criteria material selection in engineering design, Advanced Engineering Materials 6(1-2): 84-92. https://doi.org/10.1002/adem.200300554

Sirisalee, P.; Ashby, M. F.; Parks, G. T.; John Clarkson, P. 2006. Multi criteria material selection of monolithic and multi materials in engineering design, Advanced Engineering Materials 8(1-2): 48-56. https://doi.org/10.1002/adem.200500196

Stanujkic, D.; Magdalinovic, N.; Jovanovic, R. 2013. A multi-attribute decision making model based on distance from decision maker's preferences, Informatica 24(1): 103-118.

Stanujkic, D.; Zavadskas, E. K. 2015. A modified weighted sum method based on the decision-maker's preferred levels of performances, Studies in Informatics and Control 24(4): 61-470. https://doi.org/10.24846/v24i4y201510

Turskis, Z.; Zavadskas, E. K.; Antucheviciene, J. ; Kosareva, N. 2015. A hybrid model based on Fuzzy AHP and Fuzzy WASPAS for construction site selection, International Journal of Computers Communications \& Control 10(6): 113-128. https://doi.org/10.15837/ijccc.2015.6.2078

Vafaei, N.; Ribeiro, R. A.; Camarinha-Matos, L. M. 2016. Normalization techniques for multi-criteria decision making: analytical hierarchy process case study, in Doctoral Conference on Computing, Electrical and Industrial Systems. Springer, 261-269. https://doi.org/10.1007/978-3-319-31165-4_26

Xue, Y.-X.; You, J.-X.; Lai, X.-D.; Liu, H.-C. 2016. An interval-valued intuitionistic fuzzy MABAC approach for material selection with incomplete weight information, Applied Soft Computing 38: 703-713. https://doi.org/10.1016/j.asoc.2015.10.010 
Zavadskas, E.; Turskis, Z.; Antucheviciene, J.; Zakarevicius, A. 2012. Optimization of weighted aggregated sum product assessment, Elektronika ir elektrotechnika 122(6): 3-6. https://doi.org/10.5755/j01.eee.122.6.1810

Zavadskas, E.; Vilutienė, T.; Turskis, Z.; Šaparauskas, J. 2014a. Multi-criteria analysis of Projects' performance in construction, Archives of Civil and Mechanical Engineering 14(1): 114-121. https://doi.org/10.1016/j.acme.2013.07.006

Zavadskas, E. K.; Antucheviciene, J.; Razavi Hajiagha, S. H.; Hashemi, S. S. 2014b. Extension of weighted aggregated sum product assessment with interval-valued intuitionistic fuzzy numbers (WASPASIVIF), Journal Applied Soft Computing 24: 1013-1021. https://doi.org/10.1016/j.asoc.2014.08.031

Zavadskas, E. K.; Kalibatas, D.; Kalibatiene, D. 2016. A multi-attribute assessment using WASPAS for choosing an optimal indoor environment, Archives of Civil and Mechanical Engineering 16: 76-85. https://doi.org/10.1016/j.acme.2015.10.002

Zavadskas, E. K.; Turskis, Z. 2008. A new logarithmic normalization method in games theory, Informatica 19(2): 303-314.

Zavadskas, E. K.; Turskis, Z.; Kildiene, S. 2014c. State of art surveys of overviews on MCDM/MADM methods. Technological and Economic Development of Economy 20(1): 165-179. https://doi.org/10.3846/20294913.2014.892037

Zeng, Q.-L.; Li, D.-D.; Yang, Y.-B. 2013. VIKOR method with enhanced accuracy for multiple criteria decision making in healthcare management, Journal of medical systems 37(2): 1-9. https://doi.org/10.1007/s10916-012-9908-1 